\title{
Recycling of Carbon Fiber Reinforced Polymers in a Subcritical Acetic Acid Solution
}

\author{
Shreyas Shetty, Brian R. Pinkard, Igor V. Novosselov* \\ University of Washington, Mechanical Engineering Department, Seattle, WA 98195 \\ * Corresponding Author: ivn@uw.edu; [206-753-8447 / ORCID 0000-0002-6347-7450]
}




\begin{abstract}
A novel single-stage solvolysis process is demonstrated for recycling carbon fibers from an epoxy-based composite material using $50 \mathrm{wt} \%$ acetic acid solution under subcritical conditions. The process yields $100 \%$ recovery efficiency for fibers in less than $30 \mathrm{~min}$ at $300{ }^{\circ} \mathrm{C}$. Qualitative SEM / EDS analysis of the fibers reveals that the recovered fibers are entirely free of resin, while the carbon fiber surfaces were not damaged. SEM images and gravimetric measurements of the composites treated at lower temperatures and short residence times show an initial increase in mass of the CFRP samples, suggesting a two-step process, consisting of initial composite swelling due to uptake of solvent, followed by depolymerization and chemical decomposition of the polymer. FTIR and GC-MS analyses confirm resin decomposition and production of aromatic and aliphatic compounds, which could potentially be recovered for re-use.

Keywords: Carbon Fiber, Recycling, Solvolysis, Acetic Acid, Subcritical
\end{abstract}




\section{Introduction}

The use of composite materials can be dated back to the Mesopotamian era, where people glued strips of wood at different angles and multiple layers to create plywood. Today, composite materials are used in automotive and aerospace industries, sports equipment, and other consumer products. Widely used in the aviation industry, carbon fiber reinforced polymer (CFRP) primarily consists of two components: the matrix and the reinforcement. The carbon fiber is used as reinforcement, providing strength to the composite. The matrix is generally a resin polymer or epoxy, which binds the carbon fiber. The two components are combined in a controlled proportion and process, yielding the desired material properties, e.g., a high strength-to-weight ratio. CFRPs achieve tensile strength 3 to 5 times greater than stainless steel while being $30 \%$ to $50 \%$ lighter. The ubiquitous use of CFRPs raises the questions of their re-use and recycling practices from the perspective of environmental sustainability and quality of the recycled feedstock. ${ }^{1-4}$ It is estimated that $30 \%$ of the total production is disposed of as waste, including the waste generated during the manufacturing process, constituting the End-of-Life (EoL) for the composites. Therefore, recycling most of the generated waste would significantly benefit both the environmental and economic aspects of the CFRP life-cycle. ${ }^{2}$ Recycled fibers can be reintroduced for non-structural applications in various industries such as the automotive industry, sports, and consumer goods. ${ }^{5-6}$

Current CFRP recycling technologies can be broadly categorized into three groups: mechanical, thermal, and chemical processes. Mechanical processes employ a grinding step to physically break the composite material and produce grain-size particles that can be introduced in the manufacturing of CFRP composites. Thermal techniques use high temperatures to vaporize the polymer matrix and leave the fibers as a product that can be recovered. Chemical techniques utilize various solventwater mixtures that can chemically decompose the polymers, leaving the fibers intact for 
subsequent collection. Thermal and chemical processes are preferred over mechanical techniques due to their ability to recover long strands of fibers. The mechanical properties of the components manufactured using mechanically recovered fibers have inferior performance due to reduced fiber length. ${ }^{7}$

Thermal recycling of CFRP by pyrolysis requires temperatures in the 450 to $700{ }^{\circ} \mathrm{C}$ range and an inert atmosphere to degrade and volatilize the polymer matrix, yielding clean carbon fibers. ${ }^{8-10}$ In pyrolysis, the polymer matrix decomposes into two distinct product phases: gaseous low molecular weight (MW) compounds and high MW compounds such as oils and tars. Both product streams face subsequent discharge challenges, as the gaseous phase must be treated to meet emissions requirements, and the liquid phase is often classified as hazardous waste. Pyrolysis also may lead to deposition or condensation of tar and char on the recovered fibers, reducing carbon fiber quality. 9-10 The high MW species can be converted to low MW species via secondary pyrolysis at the higher temperatures or fully carbonized ${ }^{11}$, exposing the composite matrix to elevated temperatures can damage the fibers, reducing the mechanical properties of the recycled CFRP composite. ${ }^{12-14}$

Chemical recycling of CFRP, or solvolysis, chemically de-binds the CFs from the polymer matrix by dissolution and depolymerization of the polymer. Acids, bases, alcohols, and other solvents have been explored with varied success. ${ }^{15-17}$ Water has been used as a solvent at high-temperature, high-pressure (HTHP) conditions. CFRP recycling has been explored in both subcritical $\left(<374{ }^{\circ} \mathrm{C}\right)$ and supercritical water (SCW) environments, which both can be effective at decomposing organic compounds ${ }^{18-19}$ and recalcitrant chemicals. ${ }^{20}$ Decomposition rates of organic compounds in SCW are typically faster than in subcritical water conditions ${ }^{18,21-22}$, especially when an oxidant is added to promote oxidation in supercritical water. ${ }^{23-26}$ 
Several promising chemical CFRP recycling studies used acids and solvents at subcritical conditions. Das et al. ${ }^{27}$ used peracetic acid (acetic acid combined with $\mathrm{H}_{2} \mathrm{O}_{2}$ ) to decompose CFRP coupons at atmospheric pressure and moderate temperatures. Tensile strength of the fibers was reported as similar to virgin fibers, and SEM / EDS analysis confirmed little-to-no damage of the fibers. This chemical oxidation process at atmospheric pressures may allow for the continuous recycling of fibers. Still, disposal or re-use of the liquid product remains a challenge, and operating costs must be assessed against existing practices. Yu et al. ${ }^{28}$ demonstrated that ethylene glycol (EG) could be used to decompose CFRP resin at 160 to $180{ }^{\circ} \mathrm{C}$, and again the fibers retained $>95 \%$ of the virgin fibers' tensile strength.

Chemical recycling can be used for a wide size range of composite materials. Once the resin matrix is decomposed, the RCFs can be collected and cleaned before re-use. ${ }^{29-31}$ Fibers also tend to retain their original shape and tensile strength through chemical recycling. ${ }^{15,32-33}$ Chemical recycling promises the opportunity to recover and re-use the polymer decomposition products, which are captured in the liquid phase. ${ }^{34-36}$ An improved understanding of promising CFRP chemical recycling conditions, chemistries, and reaction mechanisms is needed to advance the technology toward wider commercial adoption.

This work demonstrates a novel single-stage solvolysis process for recycling carbon fibers from an unknown epoxy-based resin composite material using $50 \mathrm{wt} \%$ acetic acid solution under subcritical conditions. The process yields $100 \%$ recovery efficiency for fibers in less than $30 \mathrm{~min}$ at $300{ }^{\circ} \mathrm{C}$. The proposed mechanism is a two-step process: (i) initial composite swelling due to solvent uptake, (ii) depolymerization and chemical decomposition of the polymer.

\section{Materials and Methods}


Experimental Apparatus. Experiments were carried out in a high-pressure batch reactor system, comprising a 316 stainless steel vessel (High Pressure Equipment Co.; Erie, PA), a tube furnace (Barnstead Thermolyne Corp.; Dubuque, IA), and an internal K-type thermocouple to monitor the reaction temperature, as shown in Figure 1. The reactor vessel dimensions are $304.8 \mathrm{~mm} \mathrm{~L} \mathrm{x} 25.4$ $\mathrm{mm} \mathrm{D}$, with an internal volume of $50 \mathrm{~mL}$. Fiberglass insulation was used to insulate the reactor vessel while it was placed inside the furnace. A thermocouple data acquisition (DAQ) module with a proportional-integral-derivative (PID) controller was used to set the temperature during experiments.

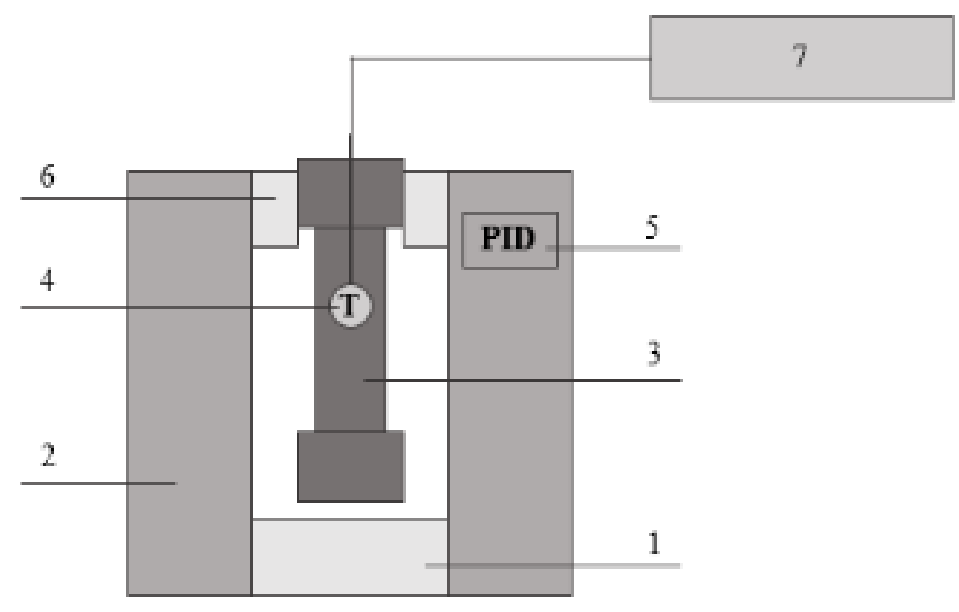

Figure 1. Schematic of a batch reactor system used for CFRP recycling consisting of (1) and (6) insulation, (2) electric tubular furnace, (3) reactor vessel (4) internal thermocouple, (5) internal PID controller, and (7) DAQ

Reagent Purity and Preparation. A thermoset CFRP composite with an unknown composition was used for all experiments. The total fraction of resin in the composite matrix was determined by thermogravimetric analysis (TGA, TA Instruments, Q50), and it was found to be in the range of 26 to $32 \%$ of the total mass of the original CFRP. The composite sample was cut into coupons 
$50 \mathrm{~mm} \times 10 \mathrm{~mm} \times 2 \mathrm{~mm}$. An aqueous solution of $50 \mathrm{wt} \%$ glacial acetic acid (99. \%, Fischer Scientific) and $50 \mathrm{wt} \%$ DI water (resistivity $18.2 \mathrm{M} \Omega-\mathrm{cm}$ ) was used in all tests.

Data Collection and Analysis. The resin removal rate $\left(R_{R}\right)$ for the composite matrix was calculated based on the mass of CFs recovered at the end of each experiment, as shown below:

$$
R_{R}=\frac{W_{C F R P}-W_{s}}{W_{C F R P}} \times 100
$$

where, $W_{C F R P}$ is the mass of CFRP composite before the start of the experiment, $W_{s}$ is the mass of the RCFs collected after drying the remained solids.

The chemical composition of the liquid samples was analyzed using ATR-FTIR (ThermoFisher Scientific, Nicolet iS 10 FTIR Spectrometer) and GC-MS (Agilent Technologies, MS: 5973; GC: 6890 with 7683 autosampler). The liquid samples were preprocessed before analyzing in the GC-MS. An aliquot of $5 \mathrm{~mL}$ was mixed with $5 \mathrm{~mL}$ of dichloromethane (DCM) to extract the organic solvents present in the sample. Sodium hydroxide (ACS reagent, $\geq 99.0 \%$, anhydrous, granular, Sigma Aldrich) was added to the extracted liquid to remove the water from the organic extracts. The organic compounds in the solution were identified by comparing the mass spectra with the inbuilt NIST database of the instrument.

Experimental Conditions. During each experiment, $35 \mathrm{~mL}$ of acetic acid solution and a $5 \mathrm{~g}$ CFRP coupon were loaded into the batch reactor and sealed. The reactor was then placed inside the tube furnace, heated to the target temperature $\left(\mathrm{T}=200-300{ }^{\circ} \mathrm{C}\right)$, and held for the desired residence time $\left(\tau_{\text {res }}=0-120 \mathrm{~min}\right)$. The residence time datum $\left(\tau_{\text {res }}=0\right)$ was set when the target experimental temperature was reached in the reactor. On average, the heat-up time was $\sim 80$ min. Expansion of the solution during heating resulted in an autogenic pressure rise to $\sim 10 \mathrm{MPa}$, keeping all reagents 
in a compressed liquid phase. After the target exposure time was reached, the reactor was cooled rapidly by immersion in cold water until it returned to room temperature. The reactor contents were then collected and filtered using Grade 1 Whatman filter paper (Millipore Sigma, Burlington, MA, US). The liquid consisting of solvent and decomposed resin was stored in a Nalgene vial for further analysis. The recycled carbon fibers (RCFs) were then rinsed with DI water and cleaned in an ultrasonic bath for $15 \mathrm{~min}$ in IPA $(99.9 \%$, Sigma Aldrich) to complete the removal of liquid residues from the recovered fibers. The cleaned fibers were then dried in a desiccant dehumidifier for $24 \mathrm{hr}$. Figure 2 shows the example of the recovered sample after $30 \mathrm{~min}$ exposure at $300{ }^{\circ} \mathrm{C}$.

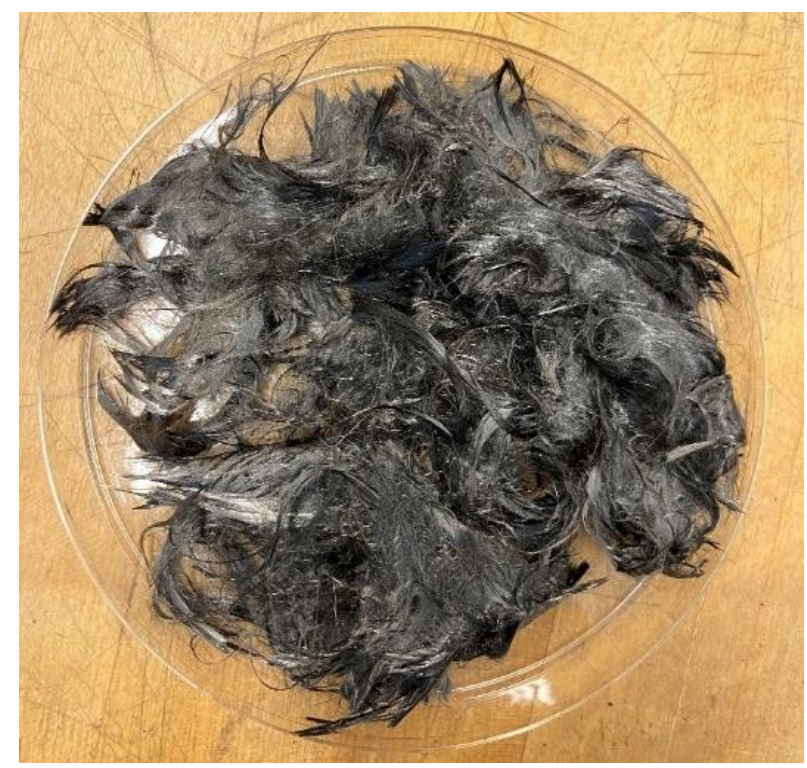

Figure 2: Clean fibers recovered after exposing the composite to a $50 \mathrm{wt} \%$ acetic acid solution at $300{ }^{\circ} \mathrm{C}$ for $30 \mathrm{~min}$.

\section{Results \& Discussion}

Analysis of Recovered Fibers. All recovered fibers were dried and weighed to assess resin decomposition during each experiment. Figure 1 shows an image of the recovered fibers from one experiment, while Table 1 shows the resin removal percentage for all conditions in the experimental matrix. 
Table 1. Resin removal rate (\%) after exposure to $50 \mathrm{wt} \%$ acetic acid solution at various temperatures and exposure times. Positive values indicate a mass decrease, while negative values indicate a weight gain, indicating swelling of the polymer matrix.

\begin{tabular}{|c|c|c|c|c|c|}
\hline \multirow{2}{*}{$\begin{array}{c}\text { Temp. } \\
\left({ }^{\circ} \mathbf{C}\right)\end{array}$} & \multicolumn{5}{|c|}{ Resin removal rate (\% ) } \\
\cline { 2 - 6 } & 0 min & $30 \mathrm{~min}$ & $60 \mathrm{~min}$ & $90 \mathrm{~min}$ & $120 \mathrm{~min}$ \\
\hline $\mathbf{2 0 0}$ & 0 & -3.96 & -3.61 & -4.40 & -5.99 \\
\hline $\mathbf{2 2 5}$ & -4.35 & -4.49 & -6.53 & -18.6 & -3.92 \\
\hline $\mathbf{2 5 0}$ & -6.82 & -3.39 & -2.04 & -16.52 & 3.98 \\
\hline $\mathbf{2 7 5}$ & -6.00 & 1.01 & 15.81 & 20.92 & 25.71 \\
\hline $\mathbf{3 0 0}$ & 2.08 & 28.49 & 31.92 & 32.97 & 31.71 \\
\hline
\end{tabular}

Figure 3 shows the resin decomposition trends at various temperatures. For all residence times at $200{ }^{\circ} \mathrm{C}, 225^{\circ} \mathrm{C}$, and $250^{\circ} \mathrm{C}$, the overall weight of the RCF coupon increases, with a maximum weight gain after 90 minutes for exposure at $225^{\circ} \mathrm{C}$ and $250{ }^{\circ} \mathrm{C}$. This trend is followed by a loss of mass at longer residence times, indicating that the exposed resins undergo an initial weight gain phase, likely due to solvent uptake into the polymer matrix, which has been previously reported. ${ }^{37-}$ ${ }^{39}$ After the initial swelling step, we infer that the polymer begins to degrade in earnest, likely due to a combination of decomposition and depolymerization mechanisms. The temperature window from $200{ }^{\circ} \mathrm{C}$ and $250{ }^{\circ} \mathrm{C}$ show relatively to be a slow swelling process (>60 min), while higher temperatures encourage a faster swelling process, followed by more rapid decomposition and depolymerization, which can be seen in weight loss of coupons exposed to the solution at $275^{\circ} \mathrm{C}$ and $300{ }^{\circ} \mathrm{C}$. Very little resin remained after treatment at $300{ }^{\circ} \mathrm{C}$ at $\tau_{\text {res }}>30 \mathrm{~min}$. We hypothesize that the swelling process plays a crucial role in the ability of the acetic acid solution to degrade the polymer matrix efficiently, and it may be possible to leverage this effect for more rapid decomposition by soaking the CFRP at a lower temperature before thermal treatment. Interestingly, that heating process $\left(\tau_{\text {res }}=0\right.$ min experiments) results in no mass gain for $\mathrm{T}=200{ }^{\circ} \mathrm{C}$, about $5-7 \%$ gain for $\mathrm{T}=225^{\circ} \mathrm{C}-275^{\circ} \mathrm{C}$, and mass loss when the sample was heated up to $\mathrm{T}=300$ 
${ }^{\circ} \mathrm{C}$. It is apparent this process is temperature-dependent, and it may be that some "activation" temperature is required for the acetic acid solution to penetrate the CFRP matrix.

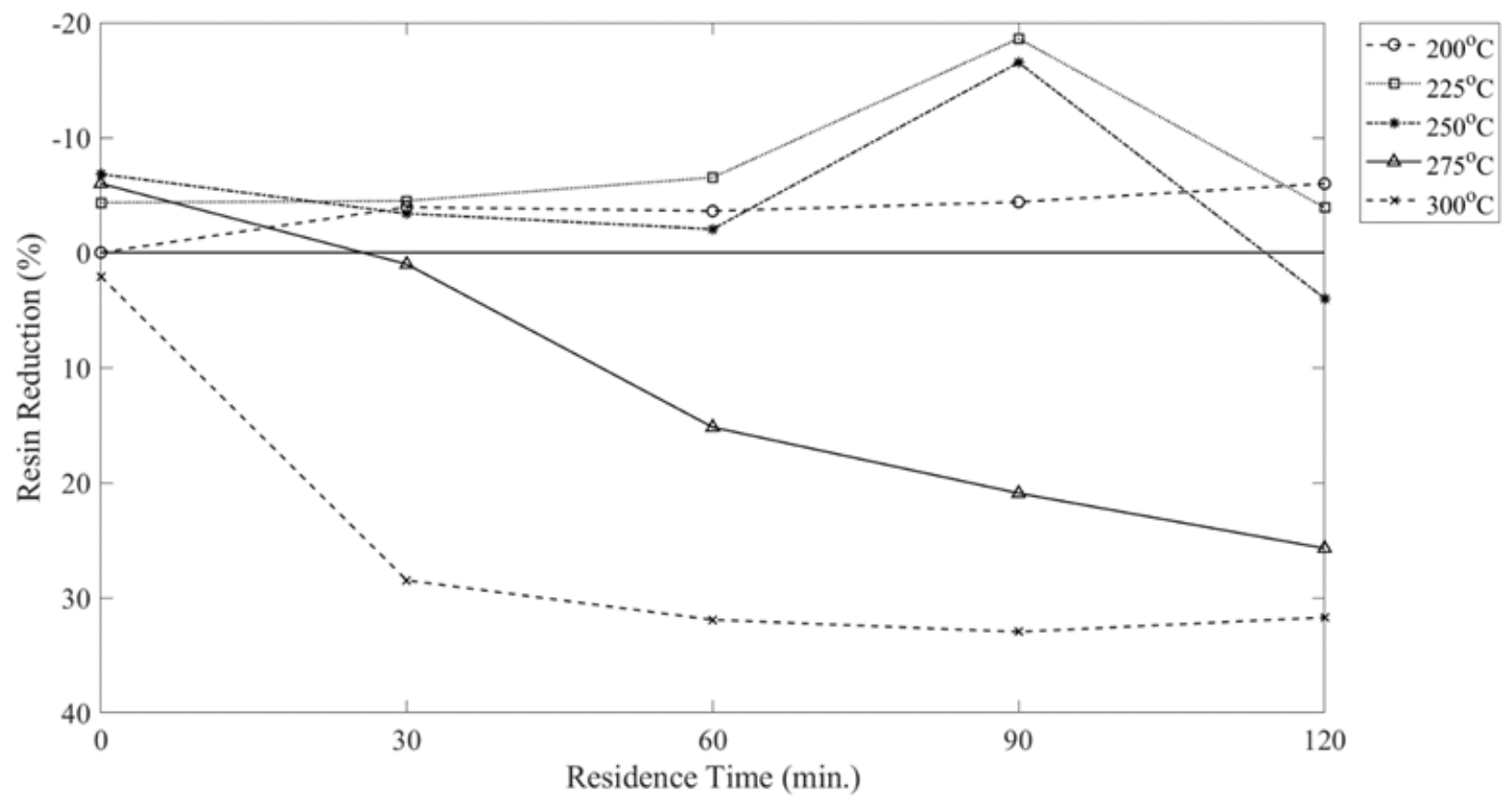

Figure 3. Resin removal rate at various experimental temperatures. The lower temperature experiments show sample mass gain before the weight reduction at the longer residence times.

SEM images of the composite matrix and recovered fibers indicate that $100 \%$ resin removal is achieved after exposure to the $50 \mathrm{wt} \%$ acetic acid solution at $300{ }^{\circ} \mathrm{C}$. Figure 4 shows SEM images of the CFRP composite before the exposure, while Figure 5 shows SEM images of the fibers 
recovered after the $300^{\circ} \mathrm{C}$ exposure experiments. EDS analysis detected no other elements present on the recovered fiber surfaces aside from carbon.
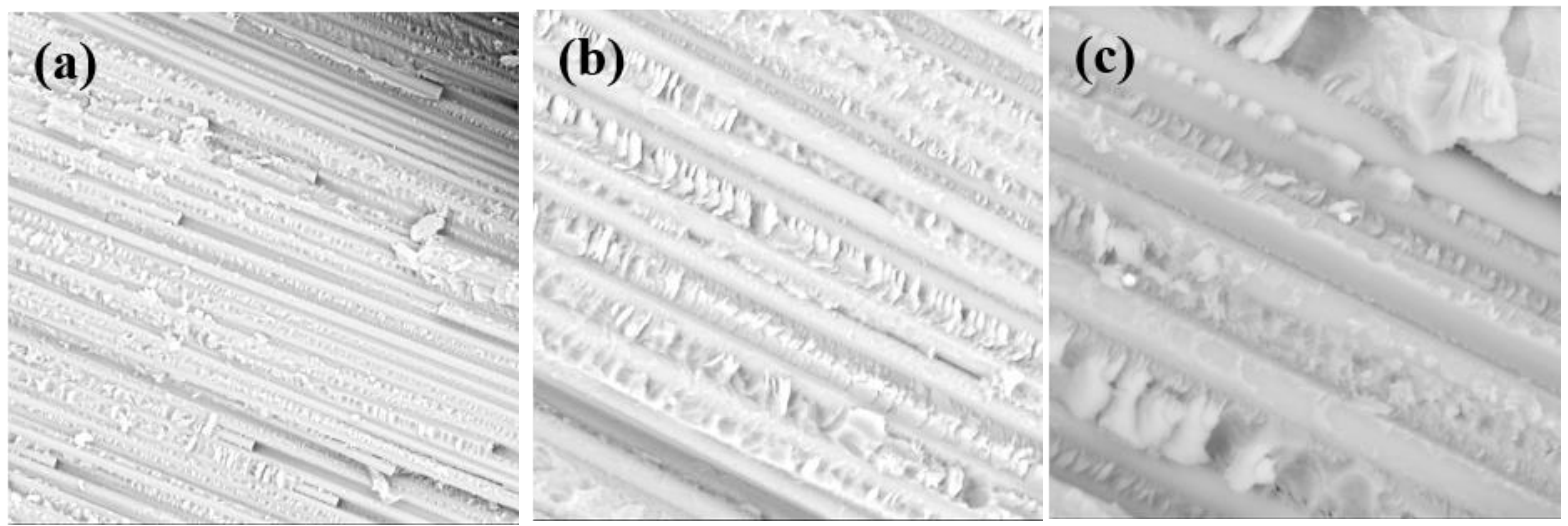

Figure 4. SEM images of CFRP composites before exposure (magnification: 850x, 2250x, and 4000x respectively)
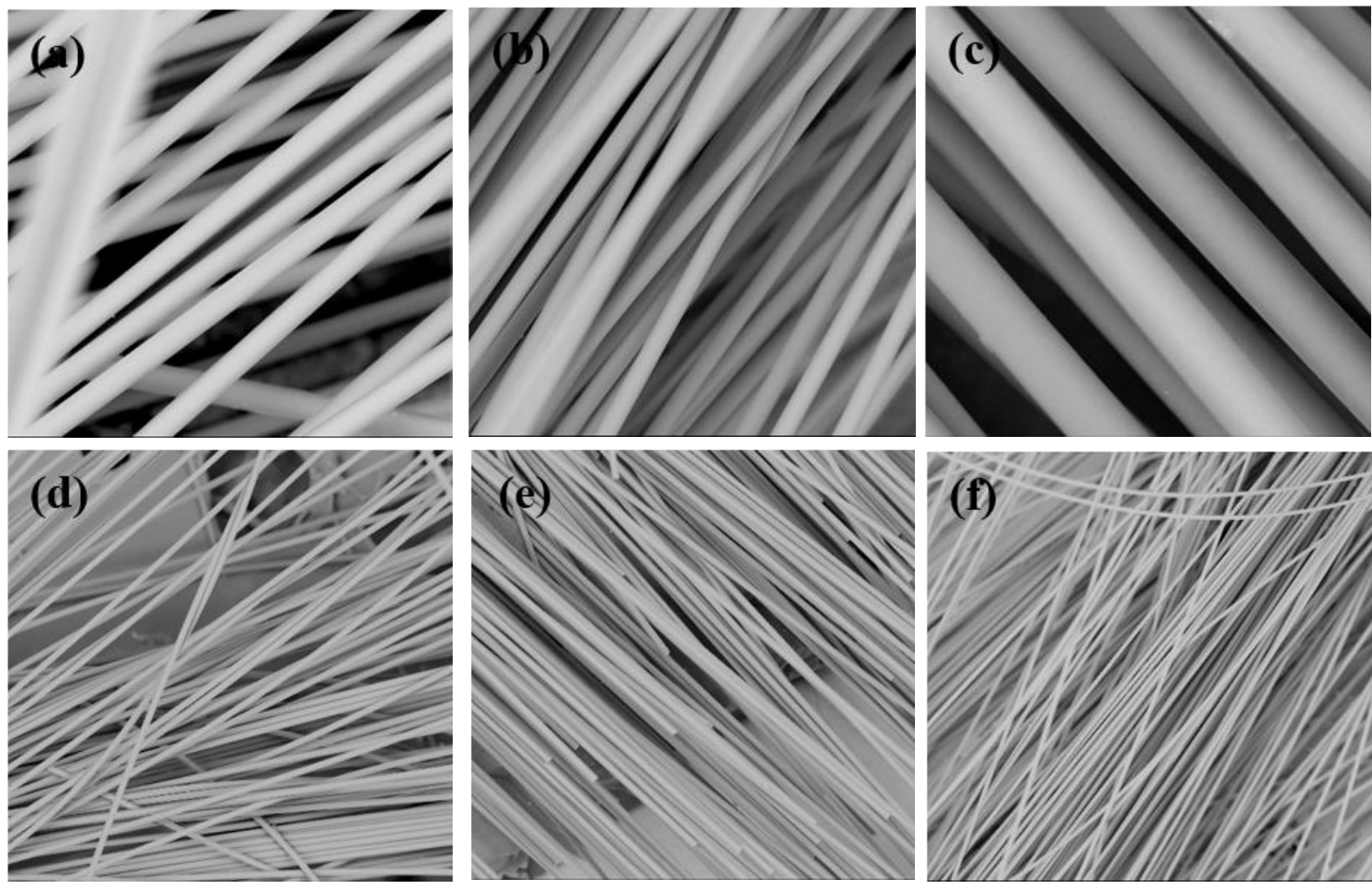

Figure 5. SEM images of recovered carbon fibers after exposure at $300{ }^{\circ} \mathrm{C}$. (a), (b), and (c) show strands of fibers with $100 \%$ resin removal (magnification: 2500x) while (d), (e), and (f) show multiple layers of clean fibers (magnification: 590x) 
Analysis of Liquid Products. The liquid products from each experiment were analyzed using ATR-FTIR to determine their composition. Figure 6 shows the ATR-FTIR spectra of the liquid products recovered after exposure at $200{ }^{\circ} \mathrm{C}$ and $300{ }^{\circ} \mathrm{C}$ for $30 \mathrm{~min}$. Peaks at $1390 \mathrm{~cm}^{-1}$ and 1703 $\mathrm{cm}^{-1}$ indicate the presence of phenolic, carbonyl, and aliphatic ketones in the recovered liquids. ${ }^{40-}$ ${ }^{42}$ The notable absence of an absorption peak in the C-N bond region at $1110 \mathrm{~cm}^{-1}$ seemingly suggests that the polymer decomposition may initiate through C-N bond cleavage. Higher temperature treatment seems to indicate the formation of more $\mathrm{C}=\mathrm{O}$ bonds via the peak at 1703 $\mathrm{cm}^{-1}$. Additional peaks corresponding to alkyl aryl ethers, amines, and aliphatic nitro compounds can be observed at $1265 \mathrm{~cm}^{-1}, 1640 \mathrm{~cm}^{-1}$, and $1370 \mathrm{~cm}^{-1}$, respectively. The formation of species with similar functional groups has been previously reported in the degradation of DGEBA epoxies which are generally used for aerospace applications. ${ }^{27-28,40-43}$

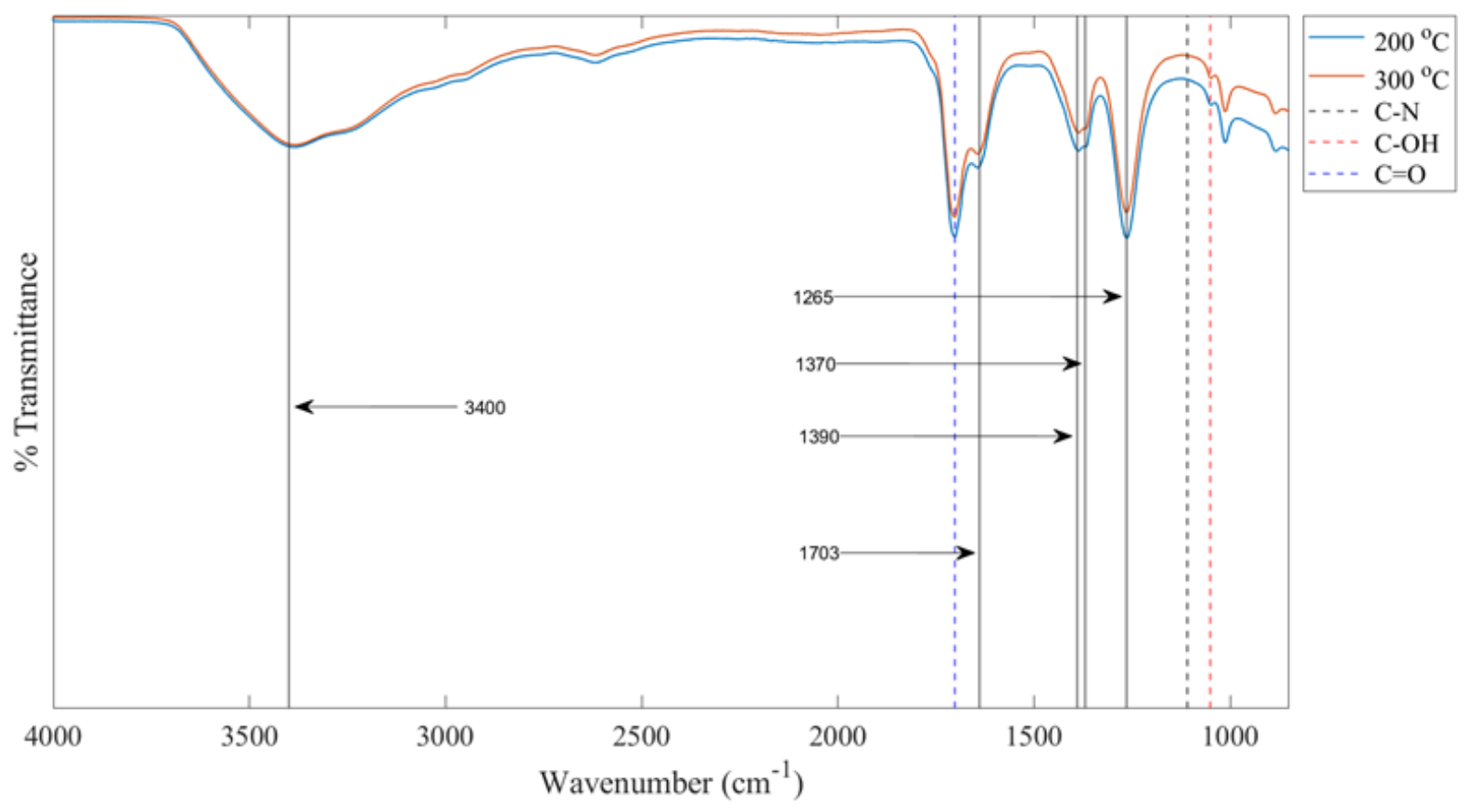

Figure 6. ATR-FTIR spectra of liquid products from CFRP decomposition experiments in $50 \mathrm{wt} \%$ acetic acid solution at $200{ }^{\circ} \mathrm{C}$ (blue) and $300{ }^{\circ} \mathrm{C}$ (red) 


\section{Conclusions}

The recycling of aerospace-grade CFRP composite material in hot-compressed $50 \mathrm{wt} \%$ acetic acid solution is demonstrated. Decomposition is witnessed to be a function of exposure time and temperature, with temperatures between 200 and $250^{\circ} \mathrm{C}$ promoting acetic-acid-induced swelling of the polymer and temperatures above $250{ }^{\circ} \mathrm{C}$ promoting more rapid polymer degradation and depolymerization. A $100 \%$ resin decomposition and fiber recovery are demonstrated at $275{ }^{\circ} \mathrm{C}$ (residence times $\sim 120 \mathrm{~min}$ ) and $300{ }^{\circ} \mathrm{C}$ (residence times $\sim 30 \mathrm{~min}$ ). Analysis of the liquid products reveals the presence of aromatic and aliphatic compounds, which could potentially be recovered for re-use.

\section{ASSOCIATED CONTENT}

\section{Supporting Information}

None

\section{AUTHOR INFORMATION}

\section{Corresponding Author}

*ivn@uw.edu; [206-753-8447]; ORCID: [0000-0002-6347-7450]

\section{Author Contributions}

The manuscript was written through the contributions of all authors. All authors have approved the final version of the manuscript.

\section{Funding Sources}


None to report

\section{ACKNOWLEDGMENTS}

The authors would like to thank Lewis Fromberg, Teagan Mach, Cody Thomsen, and Derik Stritzinger for assisting performing experiments and Bill Kuykendall for procuring CFRP sheets for testing.

\section{ABBREVIATIONS}

ATR-FTIR, attenuated total reflection Fourier transform infrared; CF, carbon fiber; CFRP, carbon fiber reinforced polymer; DAQ, data acquisition; DCM, dichloromethane; DGEBA, diglycidyl ether of bisphenol A; DI, deionized; EDS, energy dispersive X-ray spectroscopy; EoL, end-of-life; FTIR, Fourier transform infrared; GC-MS, gas chromatography - mass spectrometry; $\mathrm{H}_{2} \mathrm{O}_{2}$, hydrogen peroxide; HTHP, high-temperature, high-pressure; IPA, isopropyl alcohol; NMR, nuclear magnetic resonance; PID, proportional integral derivative; RCF, recycled carbon fiber; SCW, supercritical water; SEM, scanning electron microscope; SS, stainless steel; TOF-MS, time of flight - mass spectrometry; UD, unidirectional

\section{REFERENCES}

1. Vieira, D. R.; Vieira, R. K.; Chang Chain, M., Strategy and management for the recycling of carbon fiber-reinforced polymers (CFRPs) in the aircraft industry: a critical review. International Journal of Sustainable Development \& World Ecology 2017, 24 (3), 214-223. 2. Meng, F.; Olivetti, E. A.; Zhao, Y.; Chang, J. C.; Pickering, S. J.; McKechnie, J., Comparing life cycle energy and global warming potential of carbon fiber composite recycling technologies and waste management options. ACS Sustainable Chemistry \& Engineering 2018, 6 (8), 9854-9865.

3. Shanmugam, K.; Gadhamshetty, V.; Yadav, P.; Athanassiadis, D.; Tysklind, M.; Upadhyayula, V. K., Advanced high-strength steel and carbon fiber reinforced polymer composite body in white for passenger cars: Environmental performance and sustainable return on investment under different propulsion modes. ACS sustainable chemistry \& engineering 2019, 7 (5), 4951-4963. 
4. Giorgini, L.; Benelli, T.; Brancolini, G.; Mazzocchetti, L., Recycling of carbon fiber reinforced composite waste to close their life cycle in a cradle-to-cradle approach. Current Opinion in Green and Sustainable Chemistry 2020, 26, 100368.

5. Piñero-Hernanz, R.; García-Serna, J.; Dodds, C.; Hyde, J.; Poliakoff, M.; Cocero, M. J.; Kingman, S.; Pickering, S.; Lester, E., Chemical recycling of carbon fibre composites using alcohols under subcritical and supercritical conditions. The Journal of supercritical fluids 2008, $46(1), 83-92$.

6. Witik, R. A.; Teuscher, R.; Michaud, V.; Ludwig, C.; Månson, J.-A. E., Carbon fibre reinforced composite waste: An environmental assessment of recycling, energy recovery and landfilling. Composites. Part A, Applied science and manufacturing 2013, 49, 89-99.

7. Pietroluongo, M.; Padovano, E.; Frache, A.; Badini, C., Mechanical recycling of an endof-life automotive composite component. Sustainable Materials and Technologies 2020, 23, $\mathrm{e} 00143$.

8. Karuppannan Gopalraj, S.; Kärki, T., A review on the recycling of waste carbon fibre/glass fibre-reinforced composites: fibre recovery, properties and life-cycle analysis. $S N$ Applied Sciences 2020, 2 (3).

9. Giorgini, L.; Benelli, T.; Brancolini, G.; Mazzocchetti, L., Recycling of carbon fiber reinforced composite waste to close their life cycle in a cradle-to-cradle approach. Current opinion in green and sustainable chemistry 2020, 26, 100368.

10. Verma, S.; Balasubramaniam, B.; Gupta, R. K., Recycling, reclamation and remanufacturing of carbon fibres. Current opinion in green and sustainable chemistry 2018, 13, 86-90.

11. Davis, J.; Molnar, E.; Novosselov, I., Nanostructure transition of young soot aggregates to mature soot aggregates in diluted diffusion flames. Carbon (New York) 2020, 159, 255-265.

12. Sisti, L.; Totaro, G.; Vannini, M.; Giorgini, L.; Ligi, S.; Celli, A., Bio-Based PA11/Graphene Nanocomposites Prepared by In Situ Polymerization. Journal of nanoscience and nanotechnology 2018, 18 (2), 1169-1175.

13. Mazzocchetti, L.; Benelli, T.; D'Angelo, E.; Leonardi, C.; Zattini, G.; Giorgini, L., Validation of carbon fibers recycling by pyro-gasification: The influence of oxidation conditions to obtain clean fibers and promote fiber/matrix adhesion in epoxy composites. Composites. Part A, Applied science and manufacturing 2018, 112, 504-514.

14. Giorgini, L.; Benelli, T.; Mazzocchetti, L.; Leonardi, C.; Zattini, G.; Minak, G.; Dolcini, E.; Cavazzoni, M.; Montanari, I.; Tosi, C., Recovery of carbon fibers from cured and uncured carbon fiber reinforced composites wastes and their use as feedstock for a new composite production. Polymer composites 2015, 36 (6), 1084-1095.

15. Kim, D. H.; Lee, M.; Goh, M., Enhanced and eco-friendly recycling of carbon-fiberreinforced plastics using water at ambient pressure. ACS Sustainable Chemistry \& Engineering 2019, 8 (6), 2433-2440.

16. Kuang, X.; Zhou, Y.; Shi, Q.; Wang, T.; Qi, H. J., Recycling of epoxy thermoset and composites via good solvent assisted and small molecules participated exchange reactions. $A C S$ Sustainable Chemistry \& Engineering 2018, 6 (7), 9189-9197.

17. Reddy, K. S. K.; Gao, W.-J.; Chen, C.-H.; Juang, T.-Y.; Abu-Omar, M. M.; Lin, C.-H., Degradation of thermal-mechanically stable epoxy thermosets, recycling of carbon fiber, and reapplication of the degraded products. ACS Sustainable Chemistry \& Engineering 2021, 9 (15), 5304-5314. 
18. Pinkard, B. R.; Gorman, D. J.; Rasmussen, E. G.; Kramlich, J. C.; Reinhall, P. G.; Novosselov, I. V., Kinetics of formic acid decomposition in subcritical and supercritical watera Raman spectroscopic study. International Journal of Hydrogen Energy 2019, 44 (60), 3174531756.

19. Pinkard, B. R.; Shetty, S.; Kramlich, J. C.; Reinhall, P. G.; Novosselov, I. V., Hydrolysis of Dimethyl Methylphosphonate (DMMP) in Hot-Compressed Water. The journal of physical chemistry. A, Molecules, spectroscopy, kinetics, environment, \& general theory 2020, 124 (41), 8383-8389.

20. Wu, B.; Hao, S.; Choi, Y.; Higgins, C. P.; Deeb, R.; Strathmann, T. J., Rapid Destruction and Defluorination of Perfluorooctanesulfonate by Alkaline Hydrothermal Reaction.

Environmental science \& technology letters 2019, 6 (10), 630-636.

21. Pinkard, B. R.; Gorman, D. J.; Tiwari, K.; Kramlich, J. C.; Reinhall, P. G.; Novosselov, I. V., Review of Gasification of Organic Compounds in Continuous-Flow, Supercritical Water Reactors. Industrial \& Engineering Chemistry Research 2018, 57 (10), 3471-3481.

22. Prinçaud, M.; Aymonier, C.; Loppinet-Serani, A.; Perry, N.; Sonnemann, G., Environmental feasibility of the recycling of carbon fibers from CFRPs by solvolysis using supercritical water. ACS Sustainable Chemistry \& Engineering 2014, 2 (6), 1498-1502.

23. Pinkard, B. R.; Shetty, S.; Stritzinger, D.; Bellona, C.; Novosselov, I. V., Destruction of perfluorooctanesulfonate (PFOS) in a batch supercritical water oxidation reactor. Chemosphere 2021, 279, 130834.

24. Moore, S. J.; Pinkard, B. R.; Purohit, A. L.; Kramlich, J. C.; Reinhall, P. G.; Novosselov, I. V., Design of a Small-Scale Supercritical Water Oxidation Reactor. Part I: Experimental Characterization. Industrial \& Engineering Chemistry Research 2021, 60 (30), 11450-11457.

25. Purohit, A. L.; Misquith, J. A.; Pinkard, B. R.; Moore, S. J.; Kramlich, J. C.; Reinhall, P. G.; Novosselov, I. V., Design of a Small-Scale Supercritical Water Oxidation Reactor. Part II: Numerical Modeling. Industrial \& Engineering Chemistry Research 2021, 60 (30), 1145811469.

26. Krause, M. J.; Thoma, E.; Sahle-Damesessie, E.; Crone, B.; Whitehill, A.; Shields, E.; Gullett, B., Supercritical Water Oxidation as an Innovative Technology for PFAS Destruction. Journal of Environmental Engineering 2022, 148 (2), 05021006.

27. Das, M.; Chacko, R.; Varughese, S., An Efficient Method of Recycling of CFRP Waste Using Peracetic Acid. ACS sustainable chemistry \& engineering 2018, 6 (2), 1564-1571.

28. Yu, K.; Shi, Q.; Dunn, M. L.; Wang, T.; Qi, H. J., Carbon Fiber Reinforced Thermoset Composite with Near 100\% Recyclability. Advanced functional materials 2016, 26 (33), 60986106.

29. Asmatulu, E.; Twomey, J.; Overcash, M., Recycling of fiber-reinforced composites and direct structural composite recycling concept. Journal of composite materials 2014, 48 (5), 593608.

30. Jody, B. J.; Pomykala Jr, J. A.; Daniels, E. J.; Greminger, J. L., A process to recover carbon fibers from polymer-matrix composites in end-of-life vehicles. JOM (1989) 2004, 56 (8), 43-47.

31. Lo, J. N.; Nutt, S. R.; Williams, T. J., Recycling benzoxazine-epoxy composites via catalytic oxidation. ACS Sustainable Chemistry \& Engineering 2018, 6 (6), 7227-7231.

32. Lee, C.-K.; Kim, Y.-K.; Pruitichaiwiboon, P.; Kim, J.-S.; Lee, K.-M.; Ju, C.-S., Assessing environmentally friendly recycling methods for composite bodies of railway rolling 
stock using life-cycle analysis. Transportation research. Part D, Transport and environment 2010, 15 (4), 197-203.

33. Lee, S.-H.; Choi, H.-O.; Kim, J.-S.; Lee, C.-K.; Kim, Y.-K.; Ju, C.-S., Circulating flow reactor for recycling of carbon fiber from carbon fiber reinforced epoxy composite. The Korean journal of chemical engineering 2011, 28 (2), 449-454.

34. Ma, X.; Xu, H.; Xu, Z.; Jiang, Y.; Chen, S.; Cheng, J.; Zhang, J.; Miao, M.; Zhang, D., Closed-loop recycling of both resin and fiber from high-performance thermoset epoxy/carbon fiber composites. ACS Macro Letters 2021, 10 (9), 1113-1118.

35. Hanaoka, T.; Arao, Y.; Kayaki, Y.; Kuwata, S.; Kubouchi, M., New Approach to Recycling of Epoxy Resins Using Nitric Acid: Regeneration of Decomposed Products through Hydrogenation. ACS Sustainable Chemistry \& Engineering 2021, 9 (37), 12520-12529.

36. Jiang, T.-W.; Reddy, K. S. K.; Chen, Y.-C.; Wang, M.-W.; Chang, H.-C.; Abu-Omar, M. M.; Lin, C.-H., Recycling Waste Polycarbonate to Bisphenol A-Based Oligoesters as EpoxyCuring Agents, and Degrading Epoxy Thermosets and Carbon Fiber Composites into Useful Chemicals. ACS Sustainable Chemistry \& Engineering 2022.

37. Li, J.; Xu, P.-L.; Zhu, Y.-K.; Ding, J.-P.; Xue, L.-X.; Wang, Y.-Z., A promising strategy for chemical recycling of carbon fiber/thermoset composites: self-accelerating decomposition in a mild oxidative system. Green Chemistry 2012, 14 (12), 3260-3263.

38. Lee, M.; Kim, D. H.; Park, J.-J.; You, N.-H.; Goh, M., Fast chemical recycling of carbon fiber reinforced plastic at ambient pressure using an aqueous solvent accelerated by a surfactant. Waste Management 2020, 118, 190-196.

39. Wang, Y.; Cui, X.; Ge, H.; Yang, Y.; Wang, Y.; Zhang, C.; Li, J.; Deng, T.; Qin, Z.; Hou, X., Chemical recycling of carbon fiber reinforced epoxy resin composites via selective cleavage of the carbon-nitrogen bond. ACS Sustainable Chemistry \& Engineering 2015, 3 (12), 3332-3337.

40. Das, M.; Varughese, S., A novel sonochemical approach for enhanced recovery of carbon fiber from CFRP waste using mild acid-peroxide mixture. ACS sustainable chemistry \& engineering 2016, 4 (4), 2080-2087.

41. Dang, W.; Kubouchi, M.; Yamamoto, S.; Sembokuya, H.; Tsuda, K., An approach to chemical recycling of epoxy resin cured with amine using nitric acid. Polymer 2002, 43 (10), 2953-2958.

42. Coates, J. P., The interpretation of infrared spectra: Published reference sources. Applied spectroscopy reviews 1996, 31 (1-2), 179-192.

43. Bai, Y.; Wang, Z.; Feng, L., Chemical recycling of carbon fibers reinforced epoxy resin composites in oxygen in supercritical water. Materials \& design 2010, 31 (2), 999-1002. 